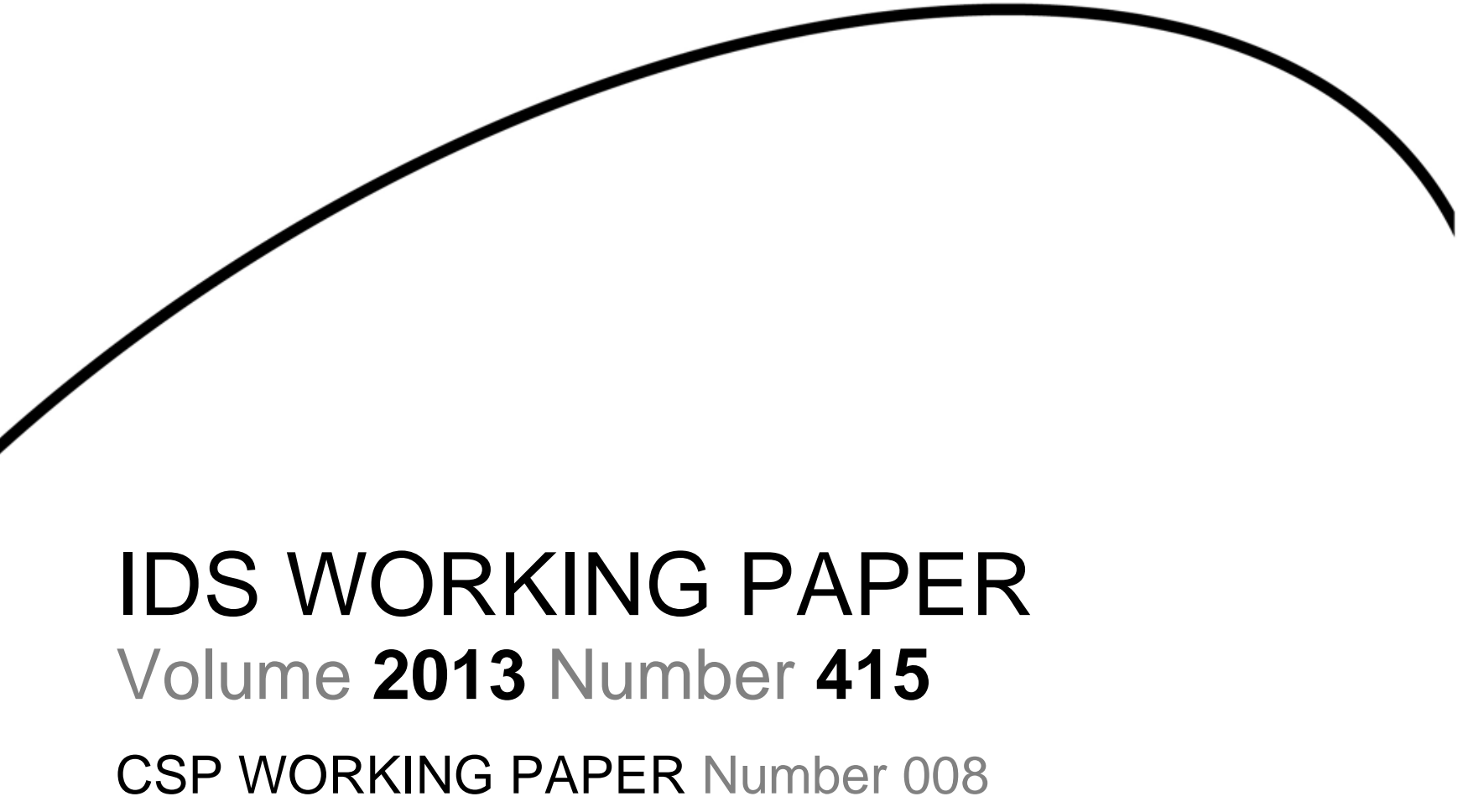

Banking on Food:

The State of Food Banks in

High-income Countries

Ugo Gentilini

January 2013

Centre for Social Protection

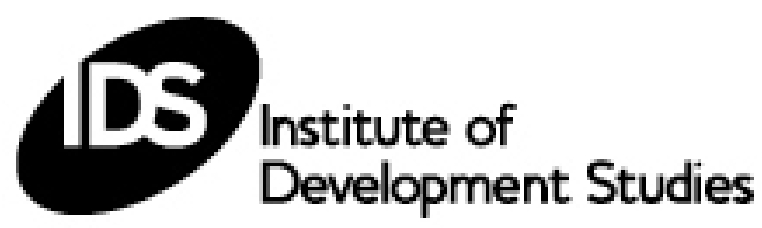


The Centre for Social Protection (CSP) supports a global network of partners working to mainstream social protection in development policy and encourage social protection systems and instruments that are comprehensive, long-term, sustainable and pro-poor. We produce research on conceptual approaches; design issues, including delivery, targeting and affordability; and impacts of different social protection initiatives.

Email: socialprotection@ids.ac.uk

Web: www.ids.ac.uk/go/research-teams/vulnerability-and-poverty-reduction-team/centre-forsocial-protection

\section{CSP WP008}

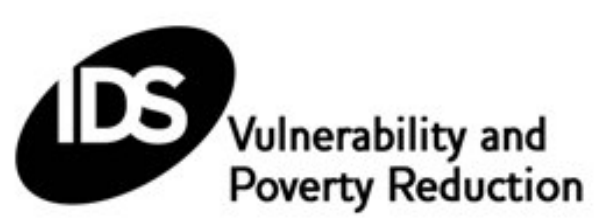

The Vulnerability and Poverty Reduction (VPR) Team aims to construct dynamic and multidimensional perspectives on vulnerability and poverty in order to transform thinking, policy and practice.

The VPR team produces working papers on social protection; conflict, violence and development; and poverty and inequality. Follow this link to view a full list of publications:

www.ids.ac.uk/research-teams/vulnerability-and-poverty-reduction-team/publications/vpr-workingpaper-series

Banking on Food: The State of Food Banks in High-income Countries

Ugo Gentilini

IDS Working Paper 415

(C) Institute of Development Studies 2013

ISSN: 2040-0209 ISBN: 978-1-78118-105-8

A catalogue record for this publication is available from the British Library.

All rights reserved. Reproduction, copy, transmission, or translation of any part of this publication

may be made only under the following conditions:

- with the prior permission of the publisher; or

- with a licence from the Copyright Licensing Agency Ltd., 90 Tottenham Court Road, London

W1P 9HE, UK,

or from another national licensing agency; or

- under the terms set out below.

This publication is copyright, but may be reproduced by any method without fee for teaching or nonprofit purposes, but not for resale. Formal permission is required for all such uses, but normally will be granted immediately. For copying in any other circumstances, or for re- use in other publications, or for translation or adaptation, prior written permission must be obtained from the publisher and a fee may be payable.

\section{Available from:}

Central Communications, Institute of Development Studies, Brighton BN1 9RE, UK

Tel: +44 (0) 1273915637 Fax: +44 (0) 1273621202

E-mail: bookshop@ids.ac.uk

Web: www.ids.ac.uk/ids/bookshop

IDS is a charitable company limited by guarantee and registered in England (No. 877338) 


\title{
Banking on Food: \\ The State of Food Banks in High-income Countries
}

\author{
Ugo Gentilini
}

\section{Summary}

Food banks provide food to charities and other grassroots organisations for supporting vulnerable populations. As such, they tend to complement more institutionalised, stateprovided safety net programmes. This paper is a first attempt to estimate the total number of people supported by food banks in high-income countries (HICs). The analysis shows that nearly 60 million people turn annually to food banks in 'rich' nations - that is, a level similar to the entire population of France or Italy and representing about 7.2 per cent of the HIC population. Such level could be considered a conservative estimate. This scenario suggests a number of implications for social protection policy, as well as opening new frontiers for food assistance practice, partnerships and applied research. The paper concludes that (i) the need for food banks will likely stay high or even increase further in the coming future; (ii) food bank models, activities and operations require further review, appraisal and documentation; (iii) debates should not confuse responses to and causes of poverty, food insecurity and socio-economic marginalisation; and (iv) the nature, context and objectives of food assistance in advanced economies are different from those in developing countries, although scope for galvanising cooperation exists.

Keywords: food assistance, food banks, food security, high-income countries, poverty, safety nets, social protection.

Ugo Gentilini is Social Protection Specialist at the United Nations World Food Programme. 


\section{Contents}

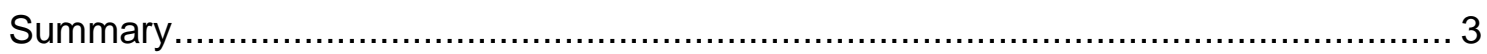

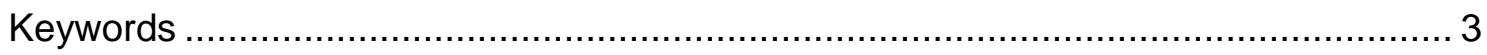

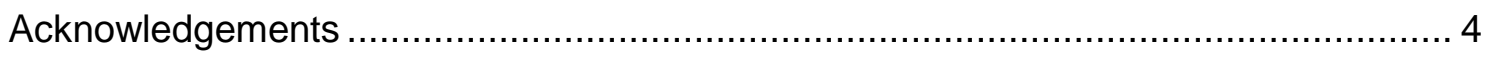

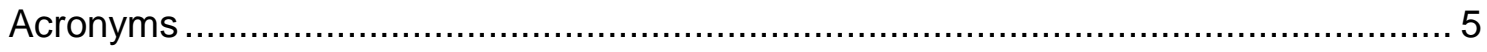

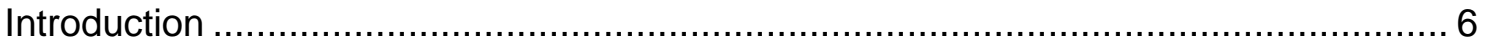

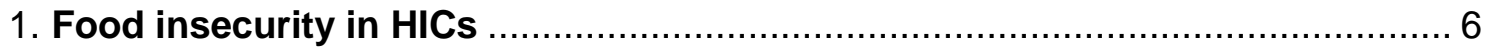

2. Basics on food assistance and food banks …............................................... 7

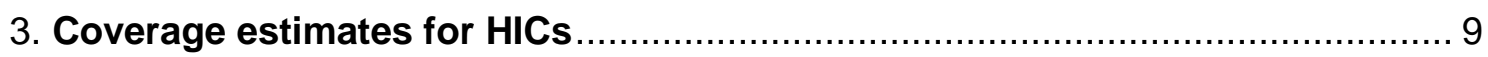

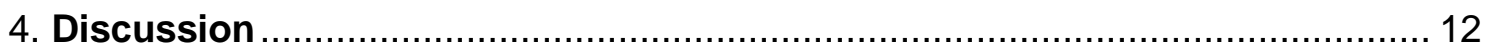

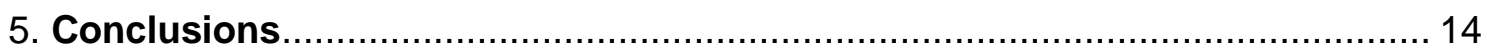

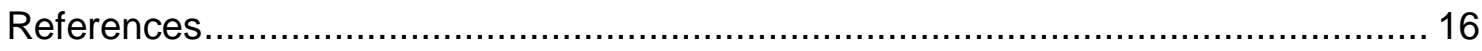

\section{Tables}

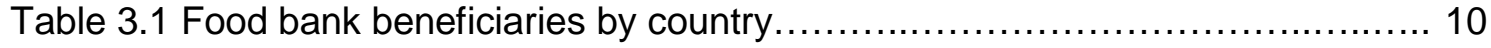

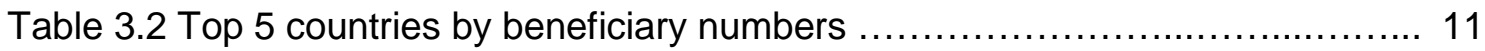

Table 3.3 Top 5 countries by beneficiary as share in total population............... 11

\section{Acknowledgements}

The analysis presented here was motivated by my humble experience as a volunteer in a food bank. This work is for a friend and food bank client, the late Pino.

A number of people provided invaluable support that helped me understand the food bank world and improve earlier drafts. In particular, special thanks go to Jeff Klein, Eberhard Lueder and Deborah Myaux. I am also grateful to, in alphabetical order, Agustín Alberti, Gerard Alix, Marina Brakalova, Deirdre de Burka, Vincent Caron, Emily Engelhard, Fintan Farrell, Maria Gosiewska, Gerd Häuser, Vaidotas Ilgius, Gabrielle Kirstein, Marco Lucchini, James Mabli, David Millar, Alen Novit, Sarah Pennell, Daniela Planchensteiner, Leon Prop, Chris Rebstock, Siobhan Rocard, Heather Roy and Natalia Stańczyk. I also had the privilege to benefit from the views of Ravi Kanbur, Patrick Webb, Lawrence Haddad, Andy Sumner, Duncan Green, Olivier De Schutter, Stephen Devereux, Aulo Gelli, Sheila Sisulu, Torben Due, Stanlake Samkange, Martin Bloem, Allan Jury, Christine Van Nieuwenhuyse, Gian Carlo Cirri, Francis Mwanza, Steve Taravella, Neil Gallagher, Cristina Ascone and Margherita Scarlato.

The paper presents my personal views and they should not be attributed to WFP. Any opinion or errors are mine only. Feedback and comments are welcome and can be sent to ugogentilini@gmail.com. 


\section{Acronyms}

EU

FEBA

HIC

MDP

MIC

SNAP

\section{European Union}

Federation of European Food Banks (translated from French)

High Income Country

Food Aid Programme for the Most Deprived Persons (European Commission) Middle Income Country

Supplemental Nutrition Assistance Program (United States) 


\section{Introduction}

In recent times, news and media have documented an upsurge in demand for food assistance emerging across high-income countries (HICs) - from North America to Europe, from Australia to Iceland ${ }^{1}$.

However, an analysis of the causes of food insecurity in HICs goes beyond the scope of this paper. Instead, it explores how growing food assistance needs are met by a particular instrument - that is, by organisations called 'food banks' that provide food to local charities and other grassroots actors for supporting vulnerable populations. The principal aim of this work is to offer a preliminary estimate of the number of people in HICs reached through those mechanisms and identify possible implications.

The importance of gauging the coverage of food banks may be three-fold: first, it may be indicative of 'real world' needs in HICs. Indeed, people access those services voluntarily, hence somewhat self-revealing their vulnerability. Second, by substituting for or complementing governmental programmes, food banks provide insights on the state of safety nets in HICs, particularly around food assistance measures ${ }^{2}$. Finally, there is underexplored potential to identify and cross-fertilise lessons and practices between food banks and the global food assistance and safety net architecture.

The remainder of the paper is structured as follows: the next section briefly reviews the state of food insecurity in HICs; section 2 sets out basic definitions and features of food assistance and food bank activities; section 3 presents estimates for food bank beneficiaries in HICs; section 4 discusses key implications and relevance of the findings, while section 5 concludes.

\section{Food insecurity in HICs}

The concept of 'food security' has been intrinsically important to frame policy issues in developing countries. Yet, it has often proved to be inherently elusive and challenging to measure. As a result, methods for its technical measurement flourish - including those based on anthropometrics, energy requirements, micronutrients, consumption patterns or qualitative measures - all of which present comparative advantages and limitations ${ }^{3}$. Unsurprisingly, therefore, HICs also tend to adopt different (and often debated) food security definitions and related indicators.

For example, in the United States the measurement of food security is based on a retrospective method involving 18 household questions. According to such an approach, in 2011 about 50 million Americans, or 15 per cent of the population, were food insecure; out of

\footnotetext{
${ }^{1}$ For example, a recent article in The Guardian defined 2012 as 'the year of food banks': http://m.guardian.co.uk/commentisfree/2012/dec/19/2012-year-of-the-food-bank. See also: http://www.guardian.co.uk/society/2012/oct/16/uk-poor-emergency-food-aid; http://www.ndp.ca/news/increase-food-bank-usersgovernment-must-take-action; http://www.ft.com/int//cms/s/0/fce77a74-e4c9-11e0-92a3-00144feabdc0.html\#axzz27eqW5Jrt; http://www.telegraph.co.uk/expat/expatnews/7566576/Icelands-new-poor-line-up-for-food.html;

http://belgafiles.com/increasingly-belgians-are-turning-to-food-banks/. For documentaries, see for example BBC's 'Britain's hidden hunger' (http://www.bbc.co.uk/programmes/b01nqcbm) and the multitude of videos broadcast on YouTube (http://www.youtube.com/results?search_query=food+bank).

${ }^{2}$ Safety nets are here defined as non-contributory transfers. They are part of broader social protection measures that also include access to social services, insurance and other contributory measures. The paper considers the terms safety nets, social assistance and social transfers as interchangeable (Gentilini and Omamo 2011).

${ }^{3}$ For instance, based on the revised undernourishment indicator, the FAO estimated that in 2010-2012 some 16 million people were food insecure in 'developed regions' (FAO et al. 2012). See Barrett (2010) and Webb et al. (2006) for a discussion on food security concepts and methods. For chronicles about food insecurity in Europe over the 1930s, see Vernon (2007). For an analysis bridging the themes of food, development and social protection from an historical perspective, see Smith (2011).
} 
these, about 6.8 million had a very low food security status ${ }^{4}$. Similarly, in Canada about 1.9 million, or 7.7 per cent of households, lived in food insecurity in 2007-2008 ${ }^{5}$. In the European Union (EU), the official food insecurity indicator includes the unaffordability of 'a meal with meat, chicken or fish every second day'. In 2010, it was estimated to affect an average of 5.8 per cent across households in the EU (15 countries); this rate increases to 8.7 per cent if the 12 new EU Member States are factored in (27 countries in total), resulting in nearly 43.6 million food insecure people ${ }^{6}$.

Yet, not all HICs adopt specific food security measures. For some contexts such as HongKong, there are no official government statistics, although literature exists on estimated poverty and food insecurity levels ${ }^{7}$. In Australia and Japan, national poverty lines ${ }^{8}$ are often deployed as proxies for food insecurity: according to latest estimates, in those countries poverty affects, respectively, 21.7 per cent (4.6 million people) and 15.7 per cent of the population (19.8 million) ${ }^{9}$.

Importantly, caution is needed when comparing food security estimates for HICs with those of developing countries. A food insecurity indicator that refers to 'a meal with meat, chicken or fish every second day' greatly differs from those typically deployed in parts of SubSaharan Africa or South Asia. The latter include measures of extreme or chronic undernutrition - e.g. the rate of children that are stunted (i.e. with low height-for-age compared to international standards) or underweight (low weight-for-age) - and which represent a major cause in child mortality and disease ${ }^{10}$. In other words, the nature and magnitude of food insecurity in developing countries is very different from that of HICs, calling for careful interpretation of data and identification of policy and programme implications.

\section{Basics on food assistance and food banks}

Before entering the food banking world, it is important to lay out key concepts and definitions. This would help to rightly contextualise the scope and nature of food bank operations within the broader realm of food assistance. In general, food assistance is here defined as the set of measures that provide access to adequate, safe and nutritious food by vulnerable populations ${ }^{11}$. Those measures can be delivered through different 'modalities' and 'providers'.

Food assistance modalities include food, vouchers and cash transfers: food transfers entail the provision of in-kind food commodities; food vouchers (also known as stamps or near-

\footnotetext{
${ }^{4}$ See Coleman-Jensen et al. (2012). The prevalence of very low food security in 2011 was 5.7 per cent, a statistically significant increase from the 5.4 per cent level of 2010.

${ }^{5}$ The estimate refers to people aged 12 or over, see: http://www.hc-sc.gc.ca/fn-an/surveill/nutrition/commun/insecurit/key-statscles-2007-2008-eng.php\#fim. See also De Schutter (2012) for an account on food insecurity in Canada.

${ }^{6}$ For rates, see EU (2012a) and Eurostat: http://appsso.eurostat.ec.europa.eu/nui/show.do?dataset=ilc_mdes03\&lang=en. In the absence of absolute numbers (million), these were estimated manually - i.e. applying the official rate (8.7\%) to the total population for EU-27 as provided by Eurostat for 2010 (or 501,120,157 people):

http://epp.eurostat.ec.europa.eu/tgm/table.do?tab=table\&init=1\&language=en\&pcode=tps00001\&plugin=1. Finally, consider that EU-27 includes various middle-income countries (e.g. Bulgaria, Lithuania).

7 The Hong-Kong Council of Social Services (http://www.hkcss.org.hk/index_e.asp) estimated that about 1.15 million people, or $17.1 \%$ of the population, live in poverty. For food insecurity issues and estimates, see a recent study by Oxfam (2011).

${ }^{8}$ National poverty lines are relative poverty lines, generally defined as 50-60\% of median income (Gentilini and Sumner 2012).

There are instances, however, where international or absolute poverty lines are used to measure poverty even in HICs. For example, see Shaefer and Edin (2012) for an analysis of US households living on less than \$2/day.

${ }^{9}$ See OECD statistics: http://stats.oecd.org/Index.aspx?Queryld=11554\&QueryType=View.

${ }^{10}$ For example, Black et al. (2008) reckoned that about one-third of child deaths are attributable to undernutrition. In particular, they estimated that underweight births and inter-uterine growth restrictions cause 2.2 million child deaths a year (around one every 15 seconds). Poor or non-existent breastfeeding explains another 1.4 million, while other deficiencies - e.g. lack of vitamin A or zinc- account for one million. In total, that is 3.5 million deaths in children under-5 years of age caused by malnutrition-related causes.

${ }^{11}$ This is consistent with the principles and tenets of the new Food Assistance Convention (United Nations 2012).
} 
cash transfers) provide access to food for a given quantity or value in identified shops; and, finally, cash transfers provide people with money, often for an amount required to meet nutritional needs. While sharing the general aim of providing access to food, these three food assistance modalities may differ conceptually and operationally ${ }^{12}$.

In terms of provision, food assistance can be provided formally and informally. On one hand, formal measures include domestic, institutionalised measures as part of national welfare regimes as shaped by social contracts between governments and citizens; on the other hand, informal measures are managed and implemented by an array of non-governmental actors, faith-based organisations, community institutions and other charities. These networks complement the more formal, public safety net system provided by the state. In practice, however, food assistance often includes a blend of formal and informal providers (e.g. government financial support to NGOs operating in the sector; or NGOs implementing government-led programmes, such as in Poland). Therefore, the differentiation of those providers should be simply interpreted as a general, first-order distinction.

Based on those two dimensions, i.e. food assistance modalities and providers, it is possible to lay out different food assistance programmes. Food banks are characterised by being 'inkind' and 'informal' programmes. This makes them fundamentally different from other food assistance measures such as the formal, voucher-based U.S. Supplemental Nutrition Assistance Program (SNAP) or the formal, in-kind U.S. Special Supplemental Nutrition Program for Woman, Infants and Children ${ }^{13}$. To some extent, the food bank system can be considered a 'safety net of the safety net', a mechanism of last resort that complements institutionalised domestic programmes (e.g. SNAP). Indeed, food banks and their local ramifications tend to support people that may not be adequately supported or, for various reasons, not reached by formal safety nets.

More specifically, food banks can be considered an intermediate agent that connects donors and beneficiaries: on one hand, they raise contributions and support from individuals, private sector corporations, farmers, manufactories, retailers and by governments themselves ${ }^{14}$. Such support can be in-kind (e.g. surplus commodities from supermarkets) or cash-based for the procurement of commodities from suitable suppliers. On the other hand, food banks help handle, store and deliver those commodities to a web of grassroots organisations. These, in turn, directly interface with needy clients by either serving meals for on-site consumption in identified locations (so-called 'soup kitchens') or by providing take-away, pre-packaged food in selected distribution points ${ }^{15}$ (i.e. 'food pantries'). In some cases, front-line distribution actors may operate outside this framework and adopt a different model for food sourcing and distribution (e.g. small charities receiving direct donations from supermarkets).

In a number of HICs, the multitude of front-line actors is coordinated by 'umbrella' organisations, such as the Red Cross and Caritas, or major national food banks. For example, about 205 initiatives are reached by Feeding America in the United States, nearly 900 by Die Tafeln in Germany, and 722 by Fareshare in the United Kingdom ${ }^{16}$. In countries like Belgium, food banks also form national federations. Most national food banks, or

\footnotetext{
${ }^{12}$ See Gentilini (2007) for a comparative analysis.

${ }^{13}$ In total, the United States has 15 domestic food assistance programmes (USDA 2012a).

${ }^{14}$ For example, in 2012 the EU has extended the current regulation providing an additional $€ 500$ million for food banking in member countries (EU 2012b; EESC 2011). As of December 2012, there is a proposal to establish a new $€ 2.5$ billon fund for 2014-2020, the 'Fund for European Aid to the Most Deprived', including a contribution of $15 \%$ by states and $85 \%$ from the Fund (EU 2012c) (see: http://ec.europa.eu/commission_2010-2014/andor/headlines/news/2012/10/20121024_en.htm). This represents a net decrease of about $€ 1$ billion compared to current levels (i.e. $€ 357$ million/year, instead of $€ 500$ million/year). In the United States, Congress appropriated about \$308.25 million in FY 2012 for The Emergency Food Assistance Program (TEFAP) supporting food banks in federal states (USDA 2012b). This represents an increase of about $\$ 70$ million compared to FY 2011. Other government initiatives supporting food banks include the Commodity Supplemental Food Program and the Food Distribution Program on Indian Reservations.

${ }^{15}$ Note that there could be further levels of decentralisation. See for example ECA (2009).

${ }^{16}$ See Cohen et al. 2010, Die Tafeln (2012) and Fareshare (2012).
} 
representatives of national federations, are also part of networks for information sharing and capacity-building, such as the Global Food Banking Network, the Federation of European Food Banks (FEBA) and Second Harvest Asia.

In recent years, the profile of food bank beneficiaries has been evolving rapidly. It not only includes the homeless, elderly, chronically poor and other vulnerable groups; increasingly, food banks are supporting single-headed households, divorced or separated individuals, teenagers, the 'working poor' and even former middle-class family members with sporadic income and growing indebtedness. Indeed, main reported causes for turning to food banks include long-term unemployment, persistent underemployment, family breakdown, debt, domestic violence, sickness, deferred or delayed payments, ineligibility to formal social protection measures, and high food prices. As it was put by a food bank official

“... when you've got people who are on the margin of just making it and there's another price rise, another change in their outgoings, they can't negotiate [the change]... something gives, and it is going to be the food. (...) The period in which people are left with no recourse to money and therefore an inability to get food on the table is longer" ${ }^{\prime 17}$.

Importantly, while the analysis here only focuses on food banks in HICs, food banks also have a significant presence in middle-income countries (MICs). For example, in Brazil food banks reach almost 1.5 million people per day ${ }^{18}$ and in South Africa about 378,000 per year ${ }^{19}$. Countries such as India, Mexico and Turkey are also ramping-up their capacity in the realm ${ }^{20}$. Somewhat surprisingly, however, the outreach of food banks in HICs as a whole has been under-investigated. The next section presents, for the first time, a set of consolidated estimates for those contexts.

\section{Coverage estimates for HICs}

Traditionally, a number of factors make it challenging to provide aggregate food banks statistics. These include the high number of actors operating in the sector, different reporting systems, diverse organisational capacities and highly decentralised and localised business models.

This paper takes advantage of recent data provided by key institutional actors. For example, comprehensive surveys were conducted in 2012 by Food Bank Canada and in 2010 by Feeding America ${ }^{21}$. In 2012, the European Commission also assembled and presented new annual data on supported beneficiaries under the continental 'Food Aid Programme for the Most Deprived Persons' (MDP) ${ }^{22}$. Regional networks, major non-governmental organisations, national food banks and research institutes provided precious validation and feedback on those data and statistics.

\footnotetext{
${ }^{17}$ http://www.guardian.co.uk/society/2012/oct/16/uk-poor-emergency-food-aid.

${ }^{18} \mathrm{http}$ ://www.sesc.com.br/mesabrasil/resultados.html. In addition to food banks, Brazil also benefits from an initiative called Restaurante Popular: these have a number of organisational and logistical features that resemble a food bank as defined in the paper, although they are government-funded and beneficiaries pay about $\$ 0.5$ for two full meals a day (the government subsidises about $\$ 2$ per person).

${ }_{19} \mathrm{http} / / /$ www.foodbank.org.za/who-we-serve.

${ }^{20}$ See, respectively, http://www.indiafoodbanking.org/documents.asp, http://www.amba.org.mx/directorio_bancos.html, and http://www.gidabankaciligi.org/.

${ }^{21}$ See Cohen et al. (2010) and Food Bank Canada (2012).

${ }^{22}$ See EU (2012d) and visit: http://ec.europa.eu/agriculture/most-deprived-persons/meetings/05-07-2012/dg-agri-1 en.pdf. Note that in the European contexts, the term 'food aid' is used to refer to support provided to food bank beneficiaries. In the development literature, food aid is defined as a form of assistance provided internationally by a foreign or donor country (Barrett and Maxwell 2005). From this perspective, the EU 'food aid' assistance is a hybrid: on one hand, the programme is (in part) financed by an 'external' party, i.e. the European Commission; but Members States are those ultimately financing the EU itself, in addition to cover part of the current programme expenses (i.e. 15 per cent of the total, as previously indicated).
} 
In general, the analysis shows that the total number of people in HICs supported by food banks is over 57 million - a level similar to the entire population of countries such as France or Italy. This includes annual unduplicated beneficiaries reached in the most recent year for which data is available. In relative terms, it represents about 7.2 per cent of the total surveyed HIC population.

The United States holds the largest number of beneficiaries, including some 37 million people: in other words, about one-in-eight Americans - or 12 per cent of the population benefit from food banks. In the EU, almost 19 million people, or six per cent of the Union's population, currently turn to food banks. With about 3.6 million people served, France's food banks are the second in coverage worldwide and the largest in Europe (19 per cent of the EU total). Italy and Spain follow with 3.3 million (18 per cent of EU) and 1.6 million people (nine per cent) respectively. Yet, Eastern European countries have the largest share of food bank beneficiaries relative to national population, including five countries (Lithuania, Slovakia, Slovenia, Romania and Hungary) with double-digit shares.

To get an insight into the overall configuration of national safety net systems, the above data on 'informal' measures was complemented by public social expenditures figures. While an econometric analysis goes beyond the scope of this paper, it notes that some countries with high social expenditures, e.g. Belgium, tend to have lower share of food bank beneficiaries (as based on participation in the MDP); conversely, countries with relatively low public social spending may show higher food bank beneficiaries (e.g. Slovakia and United States). Yet, the relationship between 'formal' government social spending and food bank beneficiary levels is far from conclusive and deserves further analysis. Tables 3.1, 3.2 and 3.3 present the discussed estimates more in detail.

Table 3.1 Food bank beneficiaries by country

\begin{tabular}{|c|c|c|c|c|}
\hline \multirow[t]{2}{*}{ Country } & \multicolumn{2}{|c|}{ Beneficiaries } & \multirow{2}{*}{$\begin{array}{c}\text { Beneficiaries as \% of total } \\
\text { population } \\
(2010)\end{array}$} & \multirow{2}{*}{$\begin{array}{l}\text { Public social expenditures } \\
\text { as } \% \text { of GDP (2011) }\end{array}$} \\
\hline & Number & Year & & \\
\hline Belgium & 205,000 & 2011 & 1.9 & 29.6 \\
\hline Bulgaria & 255,121 & 2011 & 3.4 & $\mathrm{Na}$ \\
\hline Canada & 882,188 & 2012 & 2.6 & 18.3 \\
\hline Czech Republic & 15,000 & 2011 & 0.1 & 20.9 \\
\hline Estonia & 95,394 & 2011 & 7.1 & 18.8 \\
\hline Finland & 422,000 & 2011 & 7.9 & 28.6 \\
\hline France & $3,642,991$ & 2011 & 5.8 & 32.1 \\
\hline Greece & 403,200 & 2011 & 3.5 & 23.5 \\
\hline Hong-Kong & 3,800 & 2011 & 0.1 & $\mathrm{Na}$ \\
\hline Hungary & $1,073,637$ & 2011 & 10.8 & 21.8 \\
\hline Ireland & 90,000 & 2011 & 2.0 & 23.5 \\
\hline Italy & $3,380,000$ & 2011 & 5.6 & 27.6 \\
\hline Japan & 220,000 & 2009 & 0.1 & $\mathrm{Na}$ \\
\hline Latvia & 180,000 & 2011 & 8.0 & $\mathrm{Na}$ \\
\hline Lithuania & 495,937 & 2011 & 14.9 & $\mathrm{Na}$ \\
\hline Luxemburg & 1,547 & 2011 & 0.3 & 22.5 \\
\hline Malta & 25,000 & 2011 & 6.0 & $\mathrm{Na}$ \\
\hline Poland & $3,200,000$ & 2011 & 8.4 & 20.7 \\
\hline Portugal & 478,191 & 2011 & 4.5 & 25.2 \\
\hline Romania & $2,385,433$ & 2011 & 11.1 & $\mathrm{Na}$ \\
\hline Slovakia & 715,343 & 2011 & 13.1 & 18 \\
\hline
\end{tabular}




\begin{tabular}{ccccc}
\hline Slovenia & 254,618 & 2011 & 12.5 & 24 \\
Spain & $1,667,770$ & 2011 & 3.6 & 26 \\
United States & $37,000,000$ & 2009 & 11.9 & 19.7 \\
Total & $57,092,170$ & - & 7.2 & - \\
\hline
\end{tabular}

Source: for EU beneficiaries, see EU (2012d); for the U.S., see Cohen et al. (2010); for Canada, see Food Banks Canada (2012); for others, data from relevant food banks ${ }^{23}$. Population data are from UNDESA (2011). Data on social expenditures are provided by the OECD ${ }^{24}$.

Table 3.2 Top 5 countries by beneficiary numbers

\begin{tabular}{cc}
\hline Country & Number of beneficiaries \\
United States & $37,000,000$ \\
France & $3,642,991$ \\
Italy & $3,380,000$ \\
Poland & $3,200,000$ \\
Spain & $1,667,770$ \\
\hline
\end{tabular}

Table 3.3 Top 5 countries by beneficiary as share in total population

\begin{tabular}{cc}
\hline Country & $\begin{array}{c}\text { Beneficiaries as share in } \\
\text { total population (\%) }\end{array}$ \\
Lithuania & 14.9 \\
Slovakia & 13.1 \\
Slovenia & 12.5 \\
United States & 11.9 \\
Romania & 11.1 \\
\hline
\end{tabular}

In general, these preliminary estimates on food bank beneficiaries should be considered as conservative. Indeed, a number of factors and caveats could make the actual number of beneficiaries considerably higher. These including the following:

- For EU countries, the note considered beneficiaries reached by the European Commission's MDP. This represents the most reliable, consistent and publicly available set of figures. Yet, other actors (e.g. FEBA network, churches, etc.) also provide support that partially overlaps with the MDP. To avoid double-counting, the analysis was based only on the Commission's data which, however, is underrepresentative of the actual beneficiaries in the EU. Indeed, some countries such as Germany, Netherlands, Sweden and United Kingdom are, for the moment, not supporting the initiative ${ }^{25}$. Yet, in Germany it is estimated that the Die Tafeln network reaches nearly 1.5 million people ${ }^{26}$.

- In the United States, the analysis is based on Feeding America's outreach, which only represents about 80 per cent of the American food banking system. Indeed, the

\footnotetext{
${ }^{23}$ For Japan, see http://www.2hj.org/index.php/what_is/FAQ. Hong-Kong data is provided from personal communications with Global Foodbanking Network and Feeding Hong-Kong management.

${ }^{24} \mathrm{http}: / /$ stats.oecd.org/Index.aspx?datasetcode=SOCX AGG.

${ }^{25}$ For more background on the complex political, economic, social and institutional debates around the MDP, see CBCS (2012).

${ }^{26}$ This is provided without any government support, i.e. the concept revolves around the distribution of surplus food, otherwise wasted, from supply chains to vulnerable people based on the 'tafel' concept (Die Tafeln 2012).
} 
above reasons laid out for the EU on data consistency also apply for the United States.

- For some countries such as Australia and Israel, websites and documentation are available but do not provide statistics on beneficiary numbers but, for example, only on tonnages distributed or meals served ${ }^{27}$. For the same reason (availability of beneficiary data), for Hong-Kong the paper only considered data from Feeding HongKong, although other players exist ${ }^{28}$.

- There are interesting food bank initiatives recently launched in Arab Gulf states, such as Saudi Arabia, although some time might be required to produce consolidate statistics ${ }^{29}$.

- For Iceland and Taiwan, it was not possible to gather data based on documentation or websites of available food bank organisations ${ }^{30}$.

- Estimates are based on most recent data, which includes the year 2011 for about 85 per cent of the sample. However, economic prospects and trends in demand for assistance suggest it may be reasonable to expect higher beneficiary levels for the year 2012.

- The definition of food banks adopted in the paper, including organisations that provide commodities to grassroots actors, is based on a standard framework. But there might be localised initiatives that, through various models and arrangements, provide similar services but that are more difficult to capture and may fall outside such definition (e.g. corners in small shops dedicated to pantry-type services).

- Finally, these considerations could be somewhat tempered by the fact that a number of food bank beneficiaries may also benefit from governmental safety net programmes. For example, in the United States over 40 per cent of clients served by Feeding America had not applied for SNAP since they (erroneously) assumed they were ineligible ${ }^{31}$. However, available data doesn't allow for an aggregate estimate of such 'net' beneficiaries that are supported by food banks only.

\section{Discussion}

Food banking is a sensitive and emotional topic. Accessing food banks is often a tale of economic breakdown, erosion in family bonds and psychological distress. It may also signal the weakening of the very trust underpinning social contracts between governments and citizens. As it was recently put, '... people are losing their faith in the State ${ }^{, 32}$. At the same time, food banking is also a beacon of hope in social responsibility and mutual support. In many instances, food banks represent a successful model for synergistic partnerships between civil society, the private sector and governments ${ }^{33}$.

Yet, there is little doubt that the safety net system in HICs is being stress-tested. Food banks are hardly keeping pace with current needs, while state-provided measures are either overwhelmed or face longstanding challenges. While there is a sense that food bank usage is on the rise, the magnitude documented here - about 60 million people - may indicate a general underestimation of the phenomenon. However, its root causes are far from simple and the fundamentals around their upsurge should be further investigated. From one

\footnotetext{
${ }^{27}$ See Foodbank Australia (2012) and Leket Israel (2012).

${ }^{28}$ Other food bank players include, for example, Food Angel (http://www.foodangel.org.hk/) and Foodlink

(http://www.foodlinkfoundation.org/v5/).

${ }^{29}$ See http://www.arabnews.com/node/419234.

30 See http://www.foodbank-taiwan.org.tw/.

${ }^{31}$ See chapter 7 in Cohen et al. (2010).

${ }^{32} \mathrm{http}$ ://www.spiegel.de/international/germany/poverty-in-germany-people-are-losing-their-faith-in-the-state-a-622965.html.

${ }^{33}$ See, for example, new experiments for leveraging food banks as a platform for complementary interventions:

http://www.thestar.com/news/gta/article/1177697--rethinking-the-food-bank-it-s-no-longer-just-about-handing-out-food-to-thehungry.
} 
perspective, the coexistence of large-scale food bank operations and advanced market economies may even stimulate deeper reflections on the relationship between markets, entitlements and access to food in those contexts ${ }^{34}$. To an extreme, those dynamics matter also for national security and political stability ${ }^{35}$.

The effectiveness of food bank operations hinges upon ensuring the availability of appropriate commodities on a timely basis. The fact that food banks receive limited donations to meet growing demand calls for minimising food waste throughout the food system. Therefore, the issue of food surpluses and waste is central in shaping the role of food banks in a number of countries. For example, it was recently estimated that about one third of food produced for human consumption is lost or wasted globally. This includes nearly 1.3 billion tons/year, equal to a per capita food waste in Europe and North America of about $95-115 \mathrm{~kg} / \mathrm{year}^{36}$. As a result, there are significant social and economic efficiencies to harness within the existing food system.

Although there is much discussion on the future of safety nets in HICs, and on what lessons are there for emerging economies ${ }^{37}$, it is important to ensure that such discussions are informed by a complete understanding of the safety net system in its entirety. In this regard, if formal safety nets are extensively analysed, informal mechanisms such as food banks remain surprisingly under-explored. Particularly in Europe, there is a need for conducting comprehensive surveys, assessments and mapping of existing food bank operational models, processes and volumes. Indeed, there seem to be few, if any, robust studies like Feeding America's. Given the inherently dispersed and localised nature of food bank operations, it would be important to closely benchmark and appraise existing systems to improve their coordination, reduce duplication and enhance overall efficacy. Such analysis may also help reviewing and identifying the optimal mix of food assistance modalities and providers to support people in the most suitable and context-specific manner. This might include a wider exploration of the use of voucher and cash-based transfers when feasible and appropriate.

An indirect contribution of this paper stems from showing that domestic food assistance programmes are not limited to developing countries. With very few exceptions, all HICs tend to have food assistance measures. In particular, this analysis helped a set of food assistance programmes such as food banks to surface more fully. But this is only the beginning of a journey. More analysis is required to comprehensively map, determine and analyse food assistance measures country-by-country - including HICs, MICs and low-income settings. Such efforts may be instrumental for a global understanding of food assistance measures across the world, thereby laying the basis for a global community of practice on the matter. At the same time, we should not compare apples and oranges. On one hand, it was shown that food assistance includes different modalities and providers. These characteristics lead to programmes that differ conceptually and operationally and may not be directly comparable. On the other hand, the paper underscored that food insecurity in HICs greatly differs from that in developing countries. Not only food insecurity in parts of Sub-Saharan Africa or South Asia is of complex nature and greater magnitude; but the limited capacities and challenging operating environments that characterise those contexts raise intrinsically distinct implications. In other words, food assistance in a number of low-income countries could make the difference between life and death. This renders the objectives and contexts of food assistance in high-income countries completely different from those in most developing

\footnotetext{
${ }^{34}$ Such reflection might intersect with debates on the complex processes of food price formulation in a time of growing convergence between agriculture, finance and energy sectors (see for example Lagi et al. 2011). In this regard, Amartya Sen's capability approach may provide a relevant framework for that analysis and beyond (Sen 1999).

${ }^{35}$ For recent evidence, see Arezki and Brückner (2011).

${ }^{36}$ See FAO (2011).

37 See for example The Economist (2012).
} 
countries. The recognition of such marked difference should be the starting point for any debate around food assistance in HICs versus low-income contexts.

Yet, the experience of food banks could be relevant for actors operating in the global food assistance architecture, and vice-versa. This doesn't suggest a replication of food bank operations in developing countries. As discussed, this might be neither feasible nor desirable. However, it is important to recognise that a number of relevant features shaping food bank activities could be further examined and adapted to inform the policy and implementation of food assistance programmes in developing countries.

From this perspective, new frontiers for food assistance practice, partnerships and applied research may be at hand. Urban food insecurity and programmes might be one such frontier. Indeed, food bank operations are generally implemented in urban or sub-urban areas and slums. As urbanisation in developing countries is fast-paced ${ }^{38}$, there is uncharted potential to leverage and exchange practices on urban programming. Such experience might also help to inform the strategic role of international assistance in strengthening safety nets in a range of rapidly-urbanising $\mathrm{MICs}^{39}$.

More specifically, collaboration with major food banks could be explored on a wealth of technical issues. These may include funding strategies and financial risk management; inter and infra-ministerial coordination; nutrition approaches and programmes; logistics and delivery support; market and supply-chain analysis; warehouse management; beneficiary registration methods; monitoring and reporting systems; targeting and eligibility; set-up and management of referral centres; business models and sustainable partnerships between civil society, public and private sector; institutionalisation and 'handover' of programmes to national governments; and a range of programme performance measurement and evaluation-related initiatives.

\section{Conclusions}

The paper provided a consolidated analysis of food bank beneficiaries in high-income countries. Looking ahead, the data and discussion laid out in previous sections point to four main conclusions.

First, the need for food assistance will likely be significant in the coming future. Current patterns indicate that, at least in the short term, it would be reasonable to expect the need for food assistance to keep being high or even slightly rising. It is equally evident that both governments' safety nets and the food bank system are overstretched in terms of capacity to meet current and projected needs. These dynamics pose serious concerns in terms of potential effects on social fabrics, inequality and stability. As such, they call for more policy attention than currently received, as well as for more pragmatic, multi-sectoral, evidencebased and innovative approaches in confronting and navigating the complex trade-offs that the issue involves.

Second, food bank models, activities and operations require further review, appraisal and documentation. While food banks as a whole help millions of people, they tend to do so in a fragmented, dispersed and localised manner. The resulting information gaps might be significant, particularly around beneficiary levels, targeting methods and distribution models. Overall, there is a need to map out, assess and connect the universe of initiatives more robustly and systematically, particularly in Europe. Also, it might be required to develop a

\footnotetext{
${ }^{38}$ In 2010, Asia and Africa combined housed nearly 60 per cent of the global urban population; by 2050 , such share is projected to increase to about 75 per cent (UNICEF 2012).

${ }^{39}$ For an analysis of food banks in urban areas in Southern Africa, see Warshawsky (2011). For a broader discussion on the role of international assistance in MICs, see Kanbur and Sumner (2011).
} 
uniform and consistent definition of both food banks and their beneficiaries. The formulation of such definitions might be combined with efforts to strengthen statistics and information systems, in particular to harmonising methods for data collection and reporting. In this way, future social protection policy may be based on an enhanced, coherent and more complete understanding of the nature, volume and forms of programs available on the ground.

Third, debates should not confuse responses to and causes of poverty, food insecurity and socio-economic marginalisation. Food banks provide a crucial, last-resort safety net. As such, they are often operate with emergency means to respond to complex and structural challenges spanning over economic systems, labour markets, wealth distribution and social policy. The debate around the most appropriate 'downstream' providers of food assistance whether the state, NGOs, other providers or combinations thereof - is of great importance. Indeed, it is closely connected to issues around rights, responsibilities and social contracts. However, such debate is no substitute for identifying and addressing the 'upstream', root causes of poverty, food insecurity and socio-economic marginalisation. In other words, food banks are an instrument, not an end in themselves. As such, they are part of the solution, not of the problem.

Fourth, the nature, context and objectives of food assistance in advanced economies are different from those in developing countries, although scope for galvanising cooperation exists. A range of metrics indicate an increase in food insecurity in HICs, including significant levels of chronic or absolute needs. Yet, this should be put in perspective. For example, being food insecure in Europe officially means skipping 'a meal with meat, chicken or fish every second day'. In a number of developing countries, food insecurity is life-threatening and food assistance is about survival. This, however, doesn't mean there is no scope for lessons-sharing and cross-fertilisation of experience. Indeed, food banks offer a wealth of interesting practices. For instance, they often productively connect civil society, the private sector and governments - and they do so in challenging urban environments. In this sense, some aspects of their experience could be compelling to, for example, some rapidlyurbanising areas in middle-income contexts.

In sum, the provision of food assistance attracts lively philosophical, ethical and political debates. These are often rooted in countries' history and in their competing views around the role of the state in welfare and development. Within this context, the rise of food banks should be interpreted with caution: on one hand, it may suggest a high degree of stress; on the other hand, it may indicate a high degree of responsiveness. So let there be no doubt: given the depth and breadth of those issues, the analysis offered in the paper is only scratching the surface. But the emerging scenario suggests that the phenomenon of food banks may be substantially more significant, in terms of both magnitude and implications, than generally perceived. This would require to more firmly consider food assistance, and poverty more widely, among the top policy issues to be addressed in HICs. 


\section{References}

Arezki, R. and Brückner, M. (2011) Food Prices and Political Instability, Working Paper 11/62, Washington DC: IMF

Barrett, C. (2010) 'Measuring Food Insecurity', Science 327(5967): 825-8

Barrett, C. and Maxwell, D. (2005) Food Aid After Fifty Years: Recasting Its Role, New York: Routledge

Black, R.; Allen, L.; Bhutta, Z.; Caulfield, L.; de Onis, M.; Ezzati, M.; Mathers, C. and Rivera, J. (2008) 'Maternal and Child Undernutrition: Global and Regional Exposures and Health Consequences', The Lancet 371.9608: 243-60

CBCS (Conseil Bruxellois de Coordination Sociopolitique) (2012) Food Aid: Stop or Continue? Bruxelles Informations Sociales \# 168, Brussels

Cohen, R.; Mabli, J.; Potter, F. and Zhao, Z. (2010) Hunger in America 2010: National Report for Feeding America, Princeton: Mathematica Policy Research

Coleman-Jensen, A.; Nord, M.; Andrews, M. and Carlson, S. (2012) Household Food Security in the United States in 2011, ERS Economic Research Report 141, Washington DC: USDA

De Schutter, O. (2012) End of Mission Statement: Visit to Canada by the UN Special Rapporteur on the Right to Food, Brussels

Die Tafeln (2012) Facts and Figures: December 2012, Berlin

ECA (European Court of Auditors) (2009) European Union Food Aid for Deprived Persons: An Assessment of the Objectives, the Means and the Methods Employed, Special Report 6, Luxemburg

EESC (European Economic and Social Committee) (2011) Opinion of the European Economic and Social Committee on the Amended proposal for a Regulation of the European Parliament and of the Council amending Council Regulations (EC) No.1290/2005 and (EC) No.1234/2007 as Regards Distribution of Food Products to the Most Deprived Persons in the Union, NAT/486 - CESE 70/2011 - 2008/0183 (COD), Brussels

EU (European Union) (2012a) EU Employment and Social Situation, European Commission, Quarterly Review: June, Brussels

EU (2012b) Regulation No.121/2012 of the European Parliament and of the Council of 15 February 2012 Amending Council Regulations (EC) No.1290/2005 and (EC) No.1234/2007 as Regards Distribution of Food Products to the Most Deprived Persons in the Union, Brussels

EU (2012c) Proposal for a Regulation of the European Parliament and the Council on the Fund for European Aid to the Most Deprived. COM(2012)617-Final, Brussels 
EU (2012d) European Food Aid Programme for the Most Deprived Persons in the EU: Main Results of the Distribution Plan in the Last Years. Brussels: European Commission (http://ec.europa.eu/agriculture/most-deprived-persons/meetings/05-07-2012/dg-agri1_en.pdf)

EU (2011) The Measurement of Extreme Poverty in the European Union, Brussels: European Commission

FAO, WFP \& IFAD (2012) The State of Food Insecurity in the World 2012: Economic Growth is Necessary But Not Sufficient to Accelerate Reduction in Hunger and Malnutrition, Rome

FAO (2011) Global Food Losses and Food Waste: Extent, Causes and Prevention, Rome

Fareshare (2012) Report and Financial Statements for the Year Ended, London

Food Banks Canada (2012) Hunger Count 2012: A Comprehensive Report on Hunger and Food Bank Use in Canada, and Recommendations for Change, Toronto

Foodbank Australia (2012) End Hunger Report 2012: End Hunger in Australia, Sydney

Gentilini, U. (2007) Food and Cash Transfers: A Primer, WFP Occasional Paper 18, WFP: Rome

Gentilini, U. and Omamo, S.W. (2011) 'Social Protection 2.0: Exploring Issues, Evidence and Debates in a Globalizing World', Food Policy 36.3: 329-40

Gentilini, U. and Sumner, A. (2012) What Do National Poverty Lines Tell Us About Global Poverty?, IDS Working Paper 392, Brighton: IDS

Kanbur, R. and Sumner, A. (2011) Poor Countries or Poor People? Development Assistance and the New Geography of Global Poverty, Cornell University Working Paper 2011-08, Itaha: Cornell University

Lagi, M.; Bar-Yam, Y.; Bertrand, K. and Bar-Yam, Y. (2011) The Food Crises: A Quantitative Model of Food Prices Including Speculators and Ethanol Conversion, Cambridge: New England Complex Systems Institute

Leket Israel (2012) Annual Report 2011, Raanana

Oxfam (2011) Survey on the Impact of Soaring Food Prices on Poor Families in Hong Kong, Hong Kong: Oxfam

Sen, A. (1999) Development as Freedom, New York: Oxford University Press

Shaefer, H. and Edin, K. (2012) Extreme Poverty in the United States, 1996 to 2011, National Poverty Center, Policy Brief 28, Michigan

Smith, R. (2011) 'Social Security as a Development Institution? The Relative Efficacy of Poor Relief Provisions Under the English Old Poor Law', in C. Bayly, V. Rao and S.Szreter (eds) History, Historians and Development Policy: A Necessary Dialogue, Manchester: Manchester University Press 
The Economist (2012) 'Rethinking the Welfare State: Asia's Next Revolution - Countries Across the Continent Are Building Welfare States, With a Chance to Learn from the West's Mistakes'. Available at www.economist.com/node/21562195 (8th September)

UNDESA (2011) World Population Prospects: The 2010 Revision, New York

UNICEF (2012) State of Children 2012: Children in an Urban World, New York

United Nations (2012) Food Assistance Convention, New York

USDA (2012a) The Food Assistance Landscape: FY 2011 Annual Report, ERS, Economic Information Bulletin 93, Washington DC

USDA (2012b) The Emergency Food Assistance Program. FNS, Nutrition Program Fact Sheet (March 2012), Washington DC

Vernon, J. (2007) Hunger: A Modern History, London: Harvard University Press

Warshawsky, D. (2011) Urban Food Insecurity and the Advent of Food Banking in Southern Africa, Queen's University and AFSUN, Urban Food Security Series 6, Kingston and Cape Town

Webb, P.; Coates, J.; Frongillo, E.; Rogers B.; Swindale, A. and Bilinsky P. (2006) 'Measuring Household Food Insecurity: Why It's So Important and Yet So Difficult to Do'. Journal of Nutrition 136.5: 1404S-1408S 